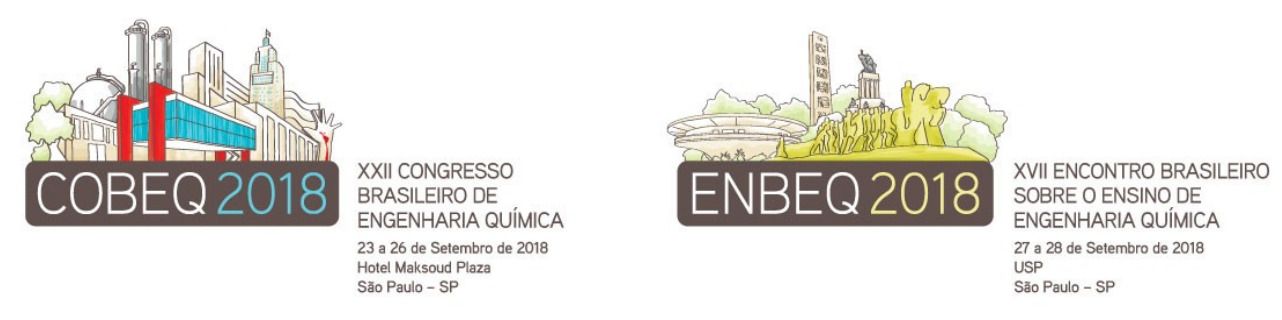

\title{
OBTENÇÃO DE NANOCELULOSE A PARTIR DE FIBRA DE COCO: PARTE I
}

\author{
MORAIS FP ${ }^{1}$, CORDEIRO NGB $^{1}$, PEREIRA Jr. $\mathrm{N}^{1}$ e ALHADEFF EM ${ }^{1}$ \\ ${ }^{1}$ Universidade Federal do Rio de Janeiro, Centro de Tecnologia, Escola de Química, \\ Departamento de Engenharia Bioquímica \\ E-mail para contato: ema@eq.ufrj.br
}

\begin{abstract}
RESUMO - O presente trabalho teve por objetivo a utilização da fibra de coco verde para obter-se cristais de nanocelulose, um material versátil com propriedades superiores à de polímeros tradicionais, que pode ser usado para substitui-los em diversas aplicações. A fibra de coco foi preparada por etapas de tratamento mecânico (cominuição e peneiração das fibra) e a seguir submetida a tratamento químico (lavadas com água, tratadas com hidróxido de sódio, branqueadas com clorito de sódio e hidrólise ácida), e após centrifugação, diálise e ultrassom. Posteriormente, as amostras finais, juntamente com as amostras bruta e intermediárias do tratamento foram analisadas em Microscópio Eletrônico de Varredura. A metodologia que alcançou melhores resultados, obtendo-se os cristais de celulose, visualizados e medidos através do $\mathrm{MEV}$, onde foram observados cristais com diâmetro igual a $63 \mu \mathrm{m}$ e comprimento de $14,34 \mu \mathrm{m}$.
\end{abstract}

\section{INTRODUÇÃO}

A busca por tecnologias que utilizem materiais renováveis não é um conceito novo. At, já existem tecnologias mais complexas que permitem o desenvolvimento de materiais renováveis que competem fortemente no aspecto de custo e desempenho com os provenientes de combustíveis fosseis. Com isso, tem-se ganhos de grande interesse para a sociedade atual, como a sustentabilidade e biodegradabilidade. O número de patentes registradas em nanocelulose pode ser usado como um bom indicador para expressar o interesse dos mercados no uso de materiais nanocelulósicos. Isogai, 2013, apud Milanez et al, 2014, reporta estudo de prospecção tecnológica que mostra um aumento exponencial do número de patentes depositadas mundialmente a partir de 2006, sobre nanocelulose, com crescimento médio de cerca de $24 \%$ ao ano. Dentre os países que contribuíram para produção das patentes mencionadas, estão: China, Finlândia, Índia, Japão, EUA e Canadá. Essas contribuições se deram por meio das empresas, universidades e centros de pesquisas nos mais diferentes tipos de segmentos de atuação (Milanez et al, 2014).

Este trabalho experimental teve por objetivo a utilização da fibra de coco, um resíduo com característica lignocelulósica, para a obtenção de cristais de nanocelulose. A metodologia escolhida para obter tal produto foi o tratamento básico para eliminação de lignina e hemicelulose, seguida de uma etapa de branqueamento das fibras, para retirar remanescentes 

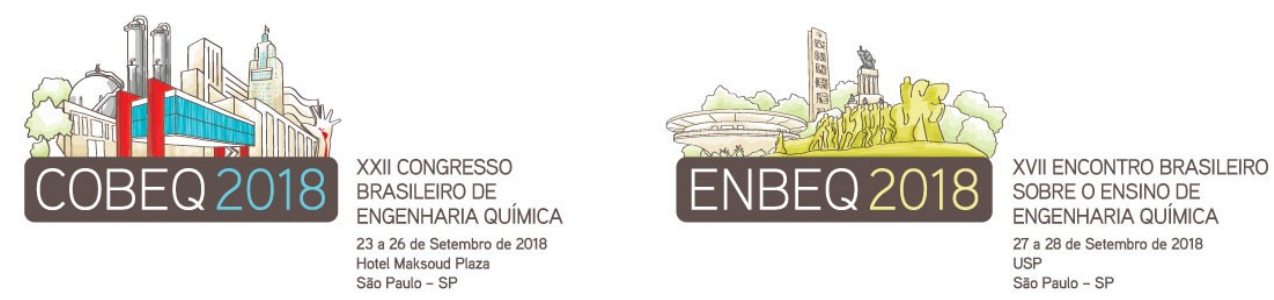

de lignina, com posterior hidrolise ácida a fim de se alcançar cristais em escala nanométrica.

\section{MATERIAIS E MÉTODOS}

A partir de prospecção tecnológica preliminar, foram selecionadas algumas publicações mais condizentes com o alvo deste trabalho, com o propósito de se obter uma metodologia mais adequada a ser aplicada (Rosa et al, 2010; Machado et al, 2014; Bacellar, 2014). As etapas comuns utilizadas em todas estas metodologias descritas na literatura, onde apenas variáveis como temperatura, tempo, concentração e reagentes diferem entre si são: obtenção da fibra, moagem, separação por tamanho de partículas (peneiras), deslignificação, branqueamento, hidrólise, centrifugação, diálise, ultrasson. Neste trabalho foram estudas quatro metodologias, obedecendo-se a mesma ordem de etapas para cada uma delas, variando-se as condições reacionais, visando à obtenção de nanocristais de celulose e a sua caracterização. A metodologia que possibilitou à obtenção de celulose cristalina será descrita neste trabalho.

\subsection{Equipamentos e Reagentes}

A moagem das fibras foi realizada em moinho de facas tipo Willye, modelo TE680, Para realizar a peneiração das fibras já moídas, se utilizou peneiras de 32, 48, 80 e 100 mesh Tyler e agitador modelo VSM 2000 da marca Viatest EOH, em bateladas de 10 minutos. Deslignificação e hidrólise realizadas em incubadora de bancada CT-712 da Cientec. Após hidrólise e etapas de lavagens seqüenciais foi utilizada centrífuga Megafuge 16R da Thermo Scientific, à $10000 \mathrm{rpm}, 10^{\circ} \mathrm{C}$ em ciclos de $10 \mathrm{~min}$. Foi utilizada membrana de diálise da marca Spectrum, 25mm modelo 3787-E25. As amostras foram postas em diálise com troca de água diária até que o $\mathrm{pH}$ em torno de 6 . As amostras diluídas foram submetidas a tratamento em ultrassom modelo Unique Ultracleaner 1400, representado na figura 22, por 20 minutos, com $40 \mathrm{kHz}$ de freqüência. Os reagentes químicos utilizados como hidróxido de sódio, clorito de sódio e ácido sulfúrico concentrado de marca Vetec. As amostras foram caracterizadas por microscopia eletrônica de varredura de superfície utilizando dois equipamentos: o Jeol JSM6406LV com detector da Thermo Electron Corporation, e o modelo Tescan Vega 3, com tensão no filamento do detector de elétrons secundários de $10 \mathrm{kV}$. Ambas as metalizações com ouro ocorreram com $20 \mu \mathrm{A}$ por 120 segundos.

\subsection{Condições de Processo}

Foram utilizadas fibra de coco seca com tamanho médio de particulados de 48 mesh, submetidas a procedimento de lavagem com água à $50^{\circ} \mathrm{C}$ por duas horas em incubadora shaker (100 rpm). A deslignificação realizada com solução de hidróxido de sódio a $2 \%(\mathrm{p} / \mathrm{v})$ e $11 \%(\mathrm{p} / \mathrm{v})$, proporção sólido:líquido de $1: 12(\mathrm{~g} / \mathrm{mL})$, à $80^{\circ} \mathrm{C}$ por duas horas $/ 100 \mathrm{rpm}$, sendo este tratamento realizado duas vezes consecutivas. $\mathrm{O}$ branqueamento realizado com solução de clorito de sódio $\left(1,5 \mathrm{~g} \mathrm{NaClO}_{2} / 150 \mathrm{~mL}\right.$ de água) a $70^{\circ} \mathrm{C}$, por duas horas a $100 \mathrm{rpm}$. A hidrólise realizada com ácido sulfúrico $50 \%(\mathrm{v} / \mathrm{v})$, proporção sólido:líquido de $1: 10$ à $45^{\circ} \mathrm{C}$ por 90 minutos $/ 100 \mathrm{rpm}$. As condições de processo de hidrólise química adotada foram: concentração de ácido sulfúrico na hidrólise de $50 \%$ (v/v), proporção sólido:líquido de 1:10, temperatura de $45^{\circ} \mathrm{C}$, tempo de hidrólise de 90 minutos $(100 \mathrm{rpm})$. 

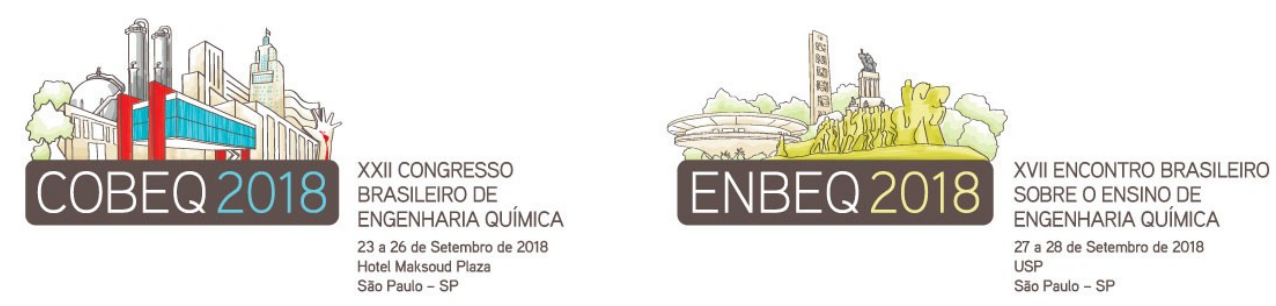

\section{RESULTADOS E DISCUSSÃO}

\subsection{Lavagem, deslignificação e branqueamento}

$\mathrm{Na}$ etapa de Branqueamento 1, através da figura 1.a (a.1 até a.4) percebe-se que as amostras tratadas com maior teor de soda cáustica tiveram uma aparência um pouco mais clara que as tratadas com menor teor de soda. Porém em ambas este clareamento não foi suficiente. O Branqueamento 2 amostras apresentadas na figura 1.b (b.1 até b.4) já bem mais livres de lignina. Assim, conseguiu-se um clareamento bem mais efetivo, sendo observado que as amostras tratadas com soda mais concentrada apresentaram um aspecto ligeiramente mais claro que as tratadas com soda a $2 \%$.

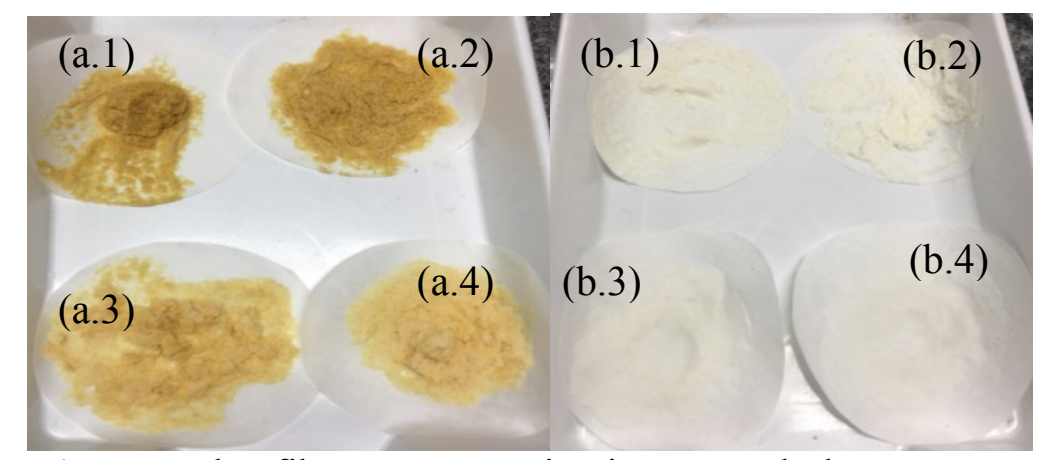

Figura 1 - 1.a - Aspecto das fibras após a primeira etapa de branqueamento 1.:a.1 e a.2 Amostras tratadas com NaOH a 2\%; a.3 e a.4 - Amostras tratadas com NaOH a 11\%; e aspecto das fibras após a etapa de branqueamento - 2: a.1 e a.2 - Amostras tratadas com $\mathrm{NaOH}$ a 2\%; b. 3 e b.4 - Amostras tratadas com NaOH a $11 \%$.

No procedimento de hidrólise com solução $50 \%$ (v/v) de ácido sulfúrico, imediatamente após adição do ácido às amostras, não ocorreu o escurecimento das mesmas, conforme mostrado na figura 2(a). Isso mostra que a concentração do ácido estava adequada. Após hidrolise ácida, as amostras apresentaram coloração marrom novamente, de acordo com a figura 2(b). Mas, assim iniciada a centrifugação, notou-se que a coloração era do liquido sobrenadante, que continha o ácido e resíduos hidrolisados (figura 2(c)). A etapa de centrifugação foi efetiva separando bem o precipitado do sobrenadante. As lavagens com água destilada de forma a aumentar o $\mathrm{pH}$, diminuindo o tempo de diálise. Por fim, obteve-se um produto com características visuais semelhantes ao descrito pela literatura e ao padrão obtido de microfibras de nanocelulose industrial.

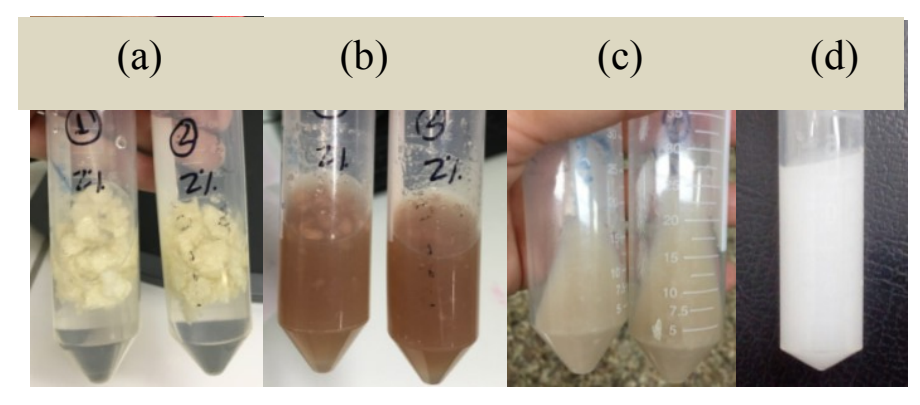

Figura 2 - (a) Amostras após a adição de ácido 50\% (v/v); (b) amostras antes, e (c) após centrifugação; (d) Padrão de microfibrilas de nanocelulose da Indústria de Papel e Celulose. 

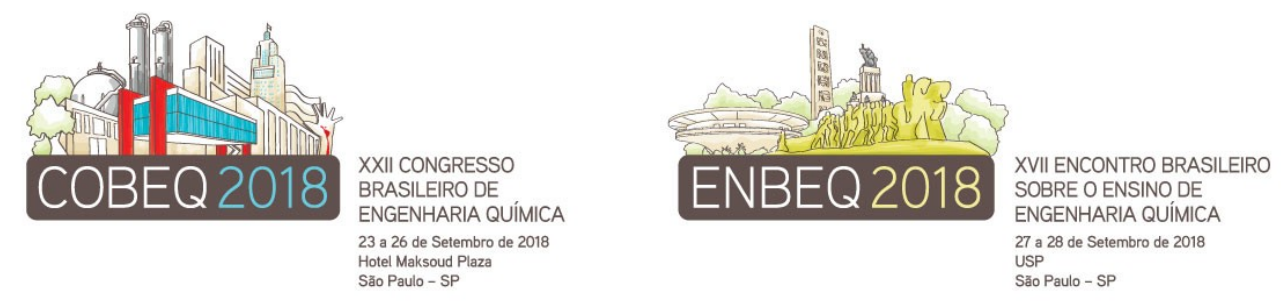

As imagens de MEV das amostras bruta (3.a), deslignificadas (3.b.1 e 3.b.2), branqueadas (3.c.1 e 3.c.2) e após hidrolise ácida (3.d) estão apresentadas na figura 3.

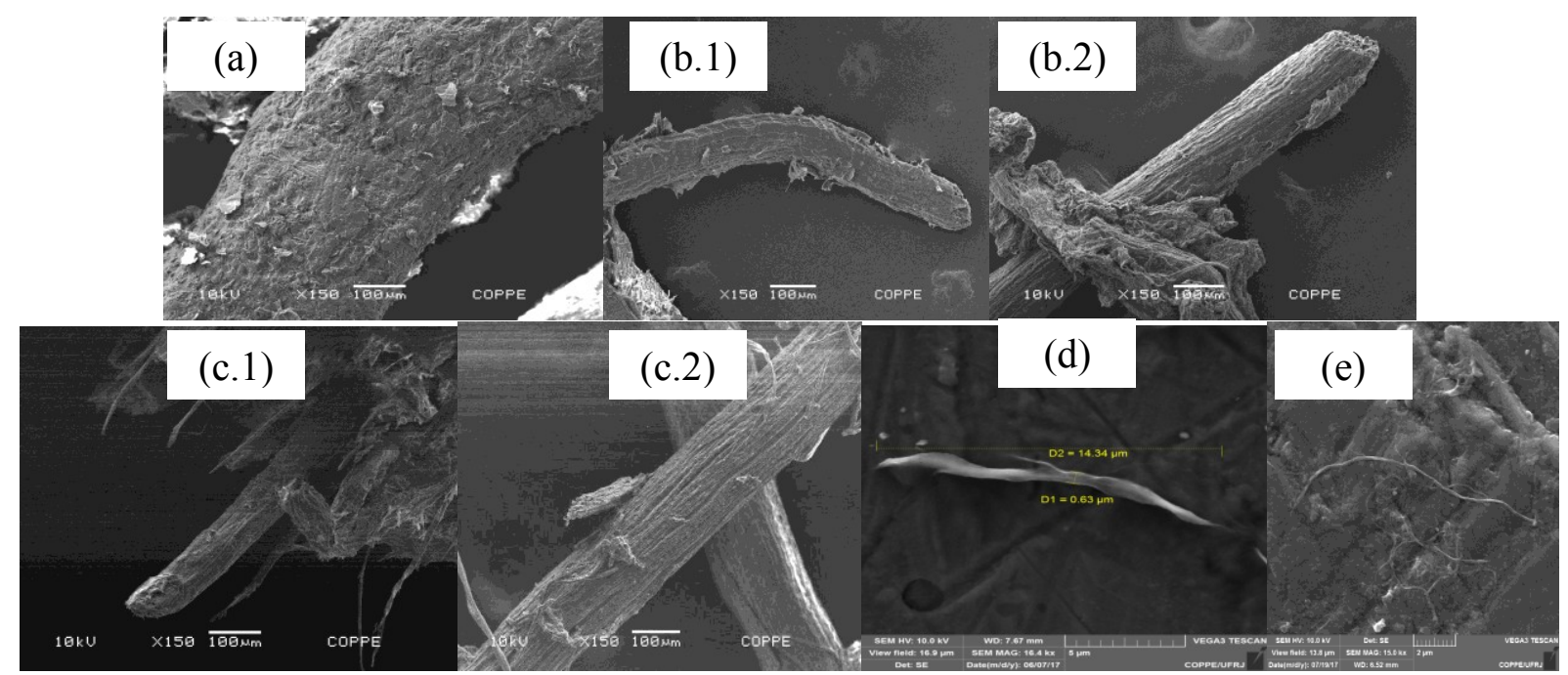

Figura 3- (a) Fibra crua vista em MEV com aumento de 150x; (b) Fibras deslignificadas: b.1- após tratamento com $\mathrm{NaOH} 2 \%$ e b.2 - após tratamento com NaOH 11\%; (c) Fibras branqueadas e deslignificadas: c. 1 - após tratamento com $\mathrm{NaOH} 2 \%$ e c. 2 - após tratamento com $\mathrm{NaOH} 11 \%$; (d) microfibra de celulose obtida $(\mathrm{NaOH} 2 \%$ - aumento de 16400x); (e) microfibra de celulose industrial com 15000x de ampliação (diâmetro $=0,14 \mu \mathrm{m}$ e cumprimento $=13,25 \mu \mathrm{m}$ ).

\section{CONCLUSÕES}

Através das imagens de MEV, as mudanças na estrutura das fibras foram evidenciadas conforme aplicados os tratamentos químicos para as condições utilizadas neste trabalho. A metodologia que alcançou melhores resultados, obtendo-se os microcristais de celulose, visualizados e medidos através do $\mathrm{MEV}$, onde pode ser observado cristal com diâmetro igual a $0,63 \mu \mathrm{m}$ e comprimento de $14,34 \mu \mathrm{m}$.

\section{REFERÊNCIAS}

BACELLAR, R. S. Avaliação de rotas para obtenção de nanocelulose a partir de fibras de coco. 2014. 161 f. Tese (Doutorado em Engenharia de Materiais e de Processos Químicos e Metalúrgicos) - Departamento de Engenharia de Materiais, PUC-Rio, Rio de Janeiro. 2014.

MACHADO, B. A. S., REIS, J. H.O., SILVA, J. B. da S.. Obtenção de nanocelulose da fibra de coco verde e incorporação em filmes biodegradáveis de amido plastificados com glicerol. Quim. Nova, v. 37, n.8, p.1275-1282, agosto 2014.

MILANEZ, D.; CHANCHETTI, L.; AMARAL, R.; FARIA, L.; ISHIKAWA, T.; GREGOLIN, J. Prospecção tecnologica dos processos de obtenção da nanocelulose a partir de indicadores tecnológicos. In: CONGRESSO ANUAL DA ABM, 69, 2014, São Paulo, 2014.

ROSA, M. F., MEDEIROS, E. S., MALMONGE, J. A., GREGORSKI, K. S.. Cellulose nanowhiskers from coconut kusk fibers: Effect of preparation conditions on their termal and morphological behavior. Carbohydrate Polymers, 81, p. 83-92, fevereiro 2010. 